\title{
The incidence, risk factors, and clinical outcomes of rhabdomyolysis associated with fenoverine prescription: a retrospective study in South Korea (1999- 2014)
}

Junhyeong Cho ${ }^{1}$, Jeonggu Na ${ }^{1}$, Eunjin Bae ${ }^{1,2}$, Tae Won Lee ${ }^{1}$, Ha Nee Jang ${ }^{3}$, Hyun Seop Cho ${ }^{3}$, Se-Ho Chang ${ }^{2,3,4}$ and Dong Jun Park $1,2,4^{*}$

\begin{abstract}
Background: Fenoverine is a spasmolytic drug that has been used to treat abdominal pain. Although sporadic case reports or case series of rhabdomyolysis associated with fenoverine have been published, there are no studies evaluating the incidence, risk factors, and clinical outcomes of rhabdomyolysis associated with fenoverine prescription.

Methods: We retrospectively reviewed the medical records of 22 patients admitted with rhabdomyolysis associated with fenoverine from January 1999 to December 2014, while excluding other well-known risk factors of rhabdomyolysis. This period was subdivided into two periods, January 1999-December 2007 and January 2008December 2014. We analyzed the clinical and laboratory characteristics, and the prognosis of fenoverine associated with rhabdomyolysis for these times.
\end{abstract}

Results: The incidence of rhabdomyolysis associated with fenoverine was $0.27 \%$ during the total period (22/8257), $0.34 \%$ in the first period (18/5298), and $0.14 \%$ in the second period $(4 / 2959)(p<0.001)$. Rhabdomyolysis occurred in 19 liver cirrhosis (LC) patients (2.03\%), whereas only 3 cases $(0.04 \%)$ occurred in non-LC patients $(p<0.001)$. Drug duration, total dose, muscle enzymes, and clinical characteristics were not different between the LC and non-LC groups. Acute renal failure (ARF) occurred in 5 patients in the LC group and 2 patients in the non-LC group $(p=0.227)$. Severity of hepatic derangement according to the Child-Pugh classification was not different between the ARF group and non$\operatorname{ARF}$ group $(p=0.227)$. Four patients died, having complications of oliguric ARF $(p=0.005)$ and underlying severe LC ( $p=0.017$ ). Higher serum lactate dehydrogenase, blood urea nitrogen, creatinine, and potassium levels but lower serum sodium levels were found in the group that died $(p=0.001)$.

(Continued on next page)

\footnotetext{
*Correspondence: drpdj@naver.com

'Department of Internal Medicine, Changwon Gyeongsang National

University Hospital, Changwon, South Korea

2Department of Internal Medicine, College of Medicine, Gyeongsang

National University, Jinju, South Korea

Full list of author information is available at the end of the article
} 
(Continued from previous page)

Conclusions: Physicians should carefully prescribe fenoverine because it may cause rhabdomyolysis, especially in patients with LC.

Keywords: Rhabdomyolysis, Risk factors, Drugs, Epidemiology, Fenoverine

\section{Background}

Rhabdomyolysis is the release of muscular cell constituents into the extracellular fluid and its circulation after a striated muscle injury [1-3]. The degree of rhabdomyolysis ranges from a subclinical rise in creatinine kinase (CK) to acute kidney injury [4-7]. The medical causes of rhabdomyolysis include drugs or toxins, muscle hypoxia, metabolic and endocrine disorders, infections, dehydration, temperature alterations, drugs, and electrolyte disturbances [4-9]. Regular and illegal drugs can cause rhabdomyolysis [4,9]; the most frequent cause of drug-induced rhabdomyolysis is the administration of HMG-CoA reductase inhibitors [9-12].

Fenoverine is a drug with a phenothiazine structure that inhibits calcium channel currents. It has a non-atropinelike spasmolytic action on muscles and is prescribed for irritable bowel syndrome with pain and abnormal intestinal transit. It has been used widely in continental Europe and Latin America to treat gastrointestinal and gynecological spasmodic disorders since 1979 [13, 14]. In Korea, it has been used since studies showed its clinical efficacy and safety for irritable bowel syndrome in 1989 . However, in several cases it has been reported as a cause of rhabdomyolysis [15-18]. One report showed that 45 cases of rhabdomyolysis were attributed to this medication over the course of 5 years [19]. The incidence of reported cases has been estimated to be around 1 per 1 million days of treatment [19]. Well-known risk factors for fenoverine-induced rhabdomyolysis are hepatic dysfunction, renal dysfunction, and concomitant use of lipid-lowering drugs [18-22]. The authors intermittently have experienced rhabdomyolysis which might be associated with fenoverine medication and retrospectively undertook this study to evaluate the clinical and laboratory characteristics and prognosis of fenoverine-associated rhabdomyolysis.

Initially, fenoverine associated rhabdomyolysis, which occurred first period (January 1999 -December 2007) was published in the 2008 master's thesis at Gyeongsang National University as case series. We again complied and analyzed the data and wrote a manuscript and presented "Clinical characteristics of rhabdomyolysis associated with fenoverine treatment" as a poster presentation (No-MP340) at the ERA-EDTA 50th Congress held in Istanbul in 2013. In that presentation, we retrospectively investigated patients with rhabdomyolysis associated with fenoverine at our hospital from January 1999 to December 2007. Based on our work, it was naturally recognized during the process of research in 2008 that fenoverine might be related with rhabdomyolysis and it was recommended that fenoverine prescriptions be limited in patients from 2008 onwards in our institution, especially patients with poor liver function. Therefore, we investigated changes in fenoverine prescriptions and compared epidemiologic changes in rhabdomyolysis associated with fenoverine before (January 1999-December 2007) and after 2008 (January 2008-December 2014).

\section{Methods}

We initially searched for 8257 patients who were prescribed fenoverine through prescription code and selected patients with the disease code of "Rhabdomyolysis" among them from January 1999 to December 2014 at our institution. Patients without temporal relationship and considered to have other causative factors except for fenoverine were excluded. We enrolled total 22 admitted patients who meet the above criteria. We divided this time into two periods, the first from January 1999 to December 2007 and the second from January 2008 to December 2014. All patients had documented medical histories and underwent a medical interview as well as a routine general physical examination. Clinical and laboratory data were reviewed for characteristics of fenoverine associated with rhabdomyolysis.

Rhabdomyolysis was defined as a serum CK concentration above $1000 \mathrm{IU} / \mathrm{L}$ (normal level, 0-170 IU/L) accompanied by clinical symptoms such as muscle pain, weakness, dark urine, and oliguria at admission [23]. We excluded patients with other causes of rhabdomyolysis, including infection, trauma, severe physical exercise, burns, toxins, drugs other than fenoverine, electrolyte abnormalities, alcohol consumption, metabolic derangements such as diabetic ketoacidosis, and endocrine abnormalities as far as possible based on medical records. Patients with evidence of an acute myocardial infarction or acute cerebral vascular accident were also excluded from the analysis.

A diagnosis of liver cirrhosis (LC) was based on clinical, laboratory, and radiological data in patients who had predisposing factors such as a history of persistent alcohol intake, chronic viral infection (hepatitis $\mathrm{B}$ or $\mathrm{C}$ ), or cryptogenic symptoms. LC patients were classified into 
Child-Pugh class A-C, employing five known clinical measures of liver disease (total bilirubin, serum albumin, prothrombin time, international normalized ratio, ascites, and hepatic encephalopathy). Child-Pugh "C" was arbitrarily defined as "Severe hepatic derangement," which was one of the statistical parameters used to evaluate the association of hepatic derangement and acute renal failure (ARF) occurrence and survival. We also divided the study group patients into subgroups according to whether ARF occurred (ARF group) or not (non-ARF group). ARF was defined as an increase in serum creatinine of more than $50 \%$ over the baseline value. The death rate was also compared between the two groups.

The study protocol was approved by the Institutional Review Board of Gyeongsang National University Hospital (IRB no. 2013-03-018).

\section{Statistical analysis}

All measurement values are expressed as the mean \pm standard deviation (SD). We used Pearson's chi-square and Fisher's exact test to analyze qualitative differences. The nonparametric Mann-Whitney U test was performed for the comparison of means in small samples of similar variance. A $p$-value less than 0.05 was taken to indicate statistical significance. Statistical analysis was carried out using SPSS for Windows software (V.21.0; IBM Corp., Armonk, NY, USA).

\section{Results}

Epidemiologic changes in fenoverine-associated rhabdomyolysis between the two periods

Twenty-seven cases of rhabdomyolysis have occurred in 8257 patients prescribed fenoverine, 21 cases in the first period and 6 cases in the second period. Five cases were excluded in analysis due to other etiologies (Fig. 1). Fenoverine was prescribed to 589 patients per year in the first period and 423 patients per year in the second period. Fenoverine was prescribed to 938 patients with liver disease (11.4\%); $16.5 \%$ in the first period (874/5298) and $2.2 \%$ in second period $(64 / 2959)(p<0.001)$ (Fig. 2). The incidence of rhabdomyolysis associated with fenoverine was $0.27 \%$ during the total period (22/8257), $0.34 \%$ in the first period $(18 / 5298)$, and $0.14 \%$ in the second period (4/2959) $(p<0.001)$ (Fig. 3). 19/22 patients with fenoverine who developed rhabdomyolysis had liver disease $(2.03 \%), 16$ in the first period and 3 in the second period, with only 3 occurrences $(0.04 \%)$ in patients with liver disease $(p<0.001)$.

\section{Clinical and laboratory characteristics of fenoverine associated with rhabdomyolysis}

Twenty-two patients were admitted to our hospital with rhabdomyolysis associated with fenoverine treatment. Fenoverine was prescribed to these patients because of abdominal cramping. Overall, 14 patients were male; the mean age was 58 years. The average duration and total

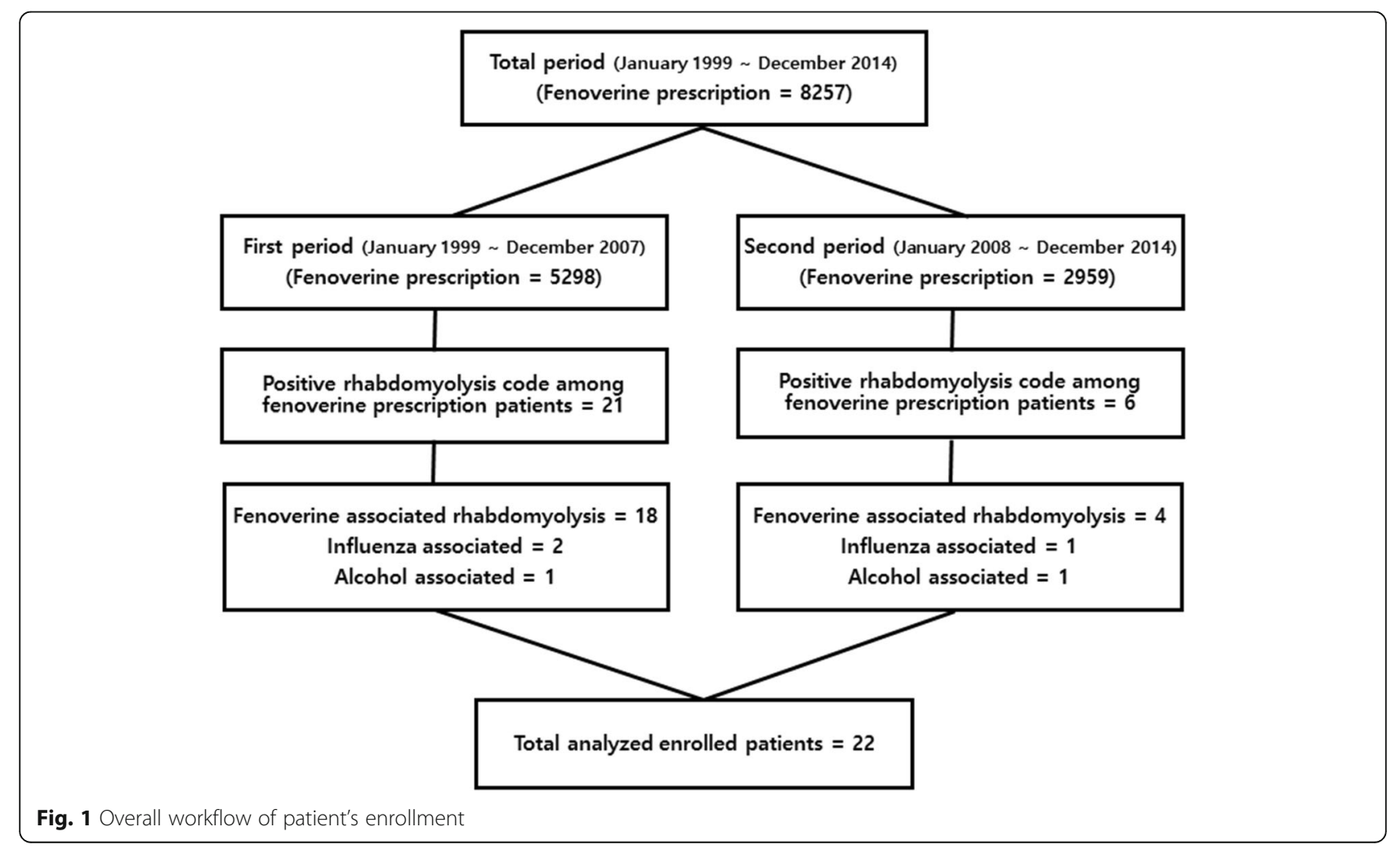




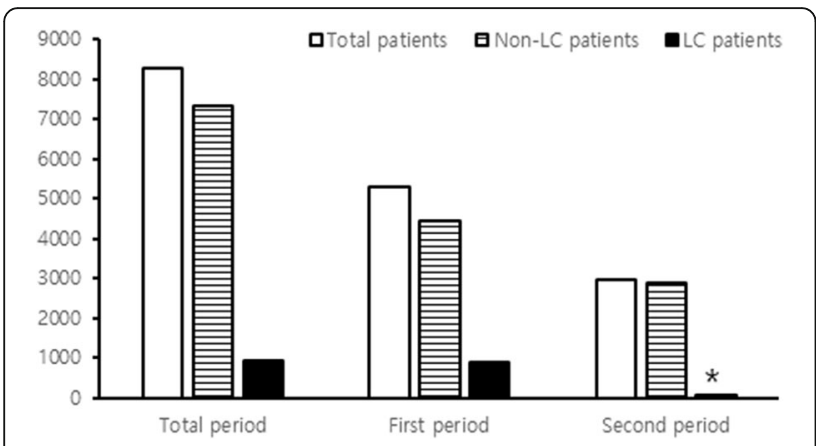

Fig. 2 The change of prescription number according to each period ( ${ }^{*} p<0.001$, compared with first period)

dose during treatment was 13.9 days and $4072 \mathrm{mg}$, respectively. Only one patient had diabetes. No patient had underlying hypertension. In total, 20 patients had muscle pain and 9 complained of muscle weakness. Four patients had oliguria and three had dark urine. The etiology of LC was as follows: hepatitis B $(n=12)$, hepatitis C $(n=2)$, alcohol $(n=4)$, and cryptogenic $(n=1)$. The patient number in Child-Pugh classes 'A', 'B', and ' $\mathrm{C}$ ' was three, seven, and nine, respectively (Table 1 ).

\section{Comparison of clinical and laboratory characteristics between the LC and non-LC groups}

Age was not statistically different between the groups. The total drug dose was $3831 \mathrm{mg}$ in the LC group and $5600 \mathrm{mg}$ in the non-LC group $(p=0.284)$. The time to admission after medication was 13.2 and 18.7 days, respectively $(p=0.328)$. There were no clinical symptom differences between the two groups (e.g., muscle pain, muscle weakness, oliguria, or dark urine). The mean duration of hospitalization was

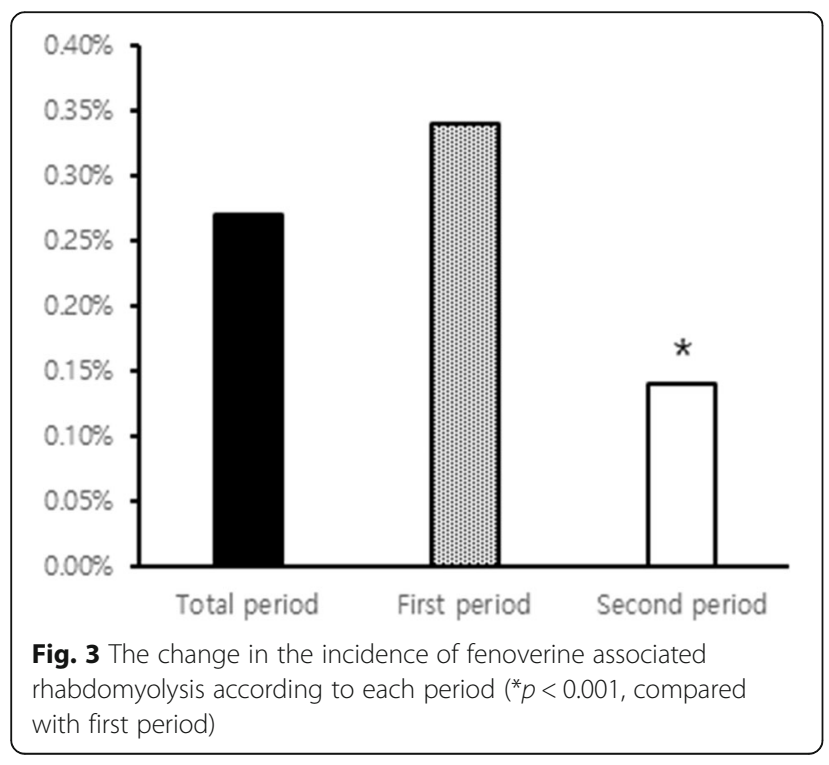

Table 1 Baseline characteristics of total patients

\begin{tabular}{|c|c|}
\hline Clinical and laboratory parameters & Total patients $(n=22)$ \\
\hline Age & $58.1 \pm 9.7$ \\
\hline \multicolumn{2}{|l|}{ Sex } \\
\hline Male (\%) & $14(63.6)$ \\
\hline Female (\%) & $8(36.4)$ \\
\hline Drug duration (days) & $13.9 \pm 8.8$ \\
\hline Drug total dose (mg) & $4072.7 \pm 2597.7$ \\
\hline $\mathrm{WBC}\left(\times 10^{3} / \mathrm{uL}\right)$ & $7.0 \pm 3.7$ \\
\hline CK (U/L) & $21,104.0 \pm 5.0$ \\
\hline LDH (U/L) & $2430.5 \pm 1623.1$ \\
\hline AST (U/L) & $1118.3 \pm 635.3$ \\
\hline $\mathrm{ALT}(\mathrm{U} / \mathrm{L})$ & $383.3 \pm 234.5$ \\
\hline Albumin (mg/dL) & $2.8 \pm 0.6$ \\
\hline BUN (mg/dL) & $29.8 \pm 26.1$ \\
\hline Creatinine (mg/dL) & $1.9 \pm 2.1$ \\
\hline Sodium (mmol/L) & $135.6 \pm 6.5$ \\
\hline Potassium (mmol/L) & $4.6 \pm 0.7$ \\
\hline Hospital days & $21.2 \pm 9.7$ \\
\hline \multicolumn{2}{|l|}{ Clinical signs and symptoms } \\
\hline Muscle pain (\%) & $20(90.9)$ \\
\hline Muscle weakness (\%) & $9(40.9)$ \\
\hline Oliguria (\%) & $4(18.2)$ \\
\hline Dark urine (\%) & $3(13.6)$ \\
\hline DM (\%) & $1(4.5)$ \\
\hline ARF (\%) & $7(31.8)$ \\
\hline Death (\%) & $4(18.2)$ \\
\hline \multicolumn{2}{|l|}{ Child-Pugh classification } \\
\hline$A(\%)$ & $3(15.8)$ \\
\hline B (\%) & $7(36.8)$ \\
\hline C (\%) & $9(47.4)$ \\
\hline \multicolumn{2}{|l|}{ Etiology of LC } \\
\hline Hepatitis B (\%) & $12(63.2)$ \\
\hline Hepatitis C (\%) & $2(10.5)$ \\
\hline Alcohol (\%) & $4(21.1)$ \\
\hline Cryptogenic (\%) & $1(5.2)$ \\
\hline
\end{tabular}

WBC White Blood Cell, CK Creatine Kinase, LDH Lactate Dehydrogenase, AST Aspartate Transaminase, ALT Alaninine Transminase, BUN Blood Urea Nitrogen, DM Diabetes Mellitus, ARF Acute Renal Failure, LC Liver Cirrhosis

longer for LC patients, although there was no statistical significance (24 vs. 11 days, $p=0.081)$. ARF occurred in 5 patients $(26.3 \%)$ in the LC group and 2 patients $(66.7 \%)$ in the non-LC group $(p=0.227)$. The serum sodium level was lower in the LC group compared to the non-LC group, though the difference was not statistically significant $(p=0.186)$. The serum blood urea nitrogen (BUN) levels and creatinine levels 
Table 2 Clinical and laboratory parameters in LC group and non-LC group

\begin{tabular}{|c|c|c|c|}
\hline $\begin{array}{l}\text { Clinical and laboratory } \\
\text { parameters }\end{array}$ & $\begin{array}{l}\text { LC group } \\
(n=19)\end{array}$ & $\begin{array}{l}\text { Non-LC group } \\
(n=3)\end{array}$ & $P$ \\
\hline Age & $57.4 \pm 9.9$ & $63.0 \pm 7.6$ & 0.361 \\
\hline Sex & & & 0.273 \\
\hline Male (\%) & $11(57.9)$ & $3(100)$ & \\
\hline Female (\%) & $8(42.1)$ & $0(0)$ & \\
\hline Drug duration (days) & $13.2 \pm 8.6$ & $18.7 \pm 10.5$ & 0.328 \\
\hline Drug total dose (mg) & $3831.6 \pm 2513.8$ & $5600.0 \pm 3152.2$ & 0.284 \\
\hline WBC $\left(\times 10^{3} / \mathrm{uL}\right)$ & $6.2 \pm 3.4$ & $12.0 \pm 1.6$ & 0.009 \\
\hline CK (U/L) & $21,132.1 \pm 16,865.7$ & $20,930.0 \pm 9363.7$ & 0.984 \\
\hline LDH (U/L) & $2416.1 \pm 1578.6$ & $1716.0 \pm 753.2$ & 0.466 \\
\hline AST (U/L) & $1088.3 \pm 638.2$ & $1403.5 \pm 748.8$ & 0.518 \\
\hline ALT (U/L) & $374.5 \pm 244.2$ & $467.5 \pm 105.4$ & 0.606 \\
\hline Albumin (g/dL) & $2.7 \pm 0.5$ & $3.5 \pm 0.8$ & 0.034 \\
\hline BUN (mg/dL) & $26.5 \pm 22.9$ & $50.6 \pm 40.9$ & 0.141 \\
\hline Creatinine (mg/dL) & $1.6 \pm 1.8$ & $3.9 \pm 3.5$ & 0.075 \\
\hline Sodium (mmol/L) & $134.9 \pm 6.5$ & $140.3 \pm 4.7$ & 0.186 \\
\hline Potassium (mmol/L) & $4.5 \pm 0.7$ & $4.9 \pm 0.7$ & 0.336 \\
\hline Hospital days & $24.0 \pm 9.5$ & $11.0 \pm 5.6$ & 0.081 \\
\hline \multicolumn{4}{|c|}{ Clinical signs and symptoms } \\
\hline Muscle pain (\%) & $17(89.5)$ & $3(100)$ & 1.000 \\
\hline Muscle weakness (\%) & $8(42.1)$ & $1(33.3)$ & 1.000 \\
\hline Oliguria (\%) & $2(10.5)$ & $2(66.7)$ & 0.371 \\
\hline Dark urine (\%) & $2(10.5)$ & $1(33.3)$ & 0.073 \\
\hline DM (\%) & $1(5.2)$ & 0 & 1.000 \\
\hline ARF (\%) & $5(26.3)$ & $2(66.7)$ & 0.227 \\
\hline Death (\%) & $4(21.1)$ & $0(0)$ & 0.603 \\
\hline \multicolumn{4}{|l|}{ Child-Pugh classification } \\
\hline A (\%) & $3(15.8)$ & NA & \\
\hline B (\%) & $7(36.8)$ & NA & \\
\hline C (\%) & $9(47.4)$ & NA & \\
\hline Etiology of LC & & NA & \\
\hline Hepatitis B (\%) & $12(63.2)$ & NA & \\
\hline Hepatitis C (\%) & $2(10.5)$ & NA & \\
\hline Alcohol (\%) & $4(21.1)$ & NA & \\
\hline Cryptogenic (\%) & $1(5.2)$ & NA & \\
\hline
\end{tabular}

WBC White Blood Cell, CK Creatine Kinase, LDH Lactate Dehydrogenase, AST Aspartate Transaminase, ALT Alaninine Transminase, BUN Blood Urea Nitrogen, DM Diabetes Mellitus, ARF Acute Renal Failure, $L C$ Liver Cirrhosis

were not different between the two groups ( $p=0.141$ and 0.075 , respectively). There were no significant differences in muscle enzyme serum levels such as CK, lactate dehydrogenase (LDH), aspartate transaminase $(\mathrm{AST})$, and alanine aminotransaminase (ALT) ( $p=$ $0.984,0.466,0.518$, and 0.606 , respectively) (Table 2 ).

\section{Comparison of clinical and laboratory characteristics between the ARF and non-ARF groups}

ARF developed in $31.8 \%$ of patients $(7 / 22)$. Five patients had LC whereas two did not have LC. Age was not significantly different between the two groups. Initial ARF was present in five patients-three patients in the LC group, and two patients in the non-LC group. ARF newly occurred during hospitalization in two LC patients. The initial sodium level was significantly lower in the ARF group, whereas the potassium level was higher in the ARF group, compared with the non-ARF group ( $p=0.020$ and 0.001 , respectively). Among the $19 \mathrm{LC}$ patients, ARF occurred in one Child-Pugh class A and four Child-Pugh class $\mathrm{C}$ patients. The mean duration of medication was 15.9 and 13.0 days in the two groups $(p=0.494)$, and the mean dose of total drug dose was 4757 and $3753 \mathrm{mg}$, respectively $(p=0.412)$. There were no significant differences in muscle enzyme serum levels such as CK, LDH, AST, and ALT $(p=0.290,0.282$, 0.085 , and 0.327 , respectively) (Table 3 ). There was no significant difference between ARF and the severity of LC classified by Child-Pugh scoring in patients with rhabdomyolysis $(p=0.312)$.

\section{Clinical outcomes}

Four instances of patient mortality occurred (18.2\%). All four deceased patients had complications of $\mathrm{LC}$, and there were no deaths in the non-LC group $(p=0.603)$ (Table 1). Higher mortality occurred in the ARF group $(p=0.005)$ (Table 2). All deceased patients experienced hepatic and renal failure. All surviving patients recovered from ARF. There were no differences in clinical symptoms associated with rhabdomyolysis such as muscular symptoms, oliguria, and dark urine between the deceased and living groups (Table 4). Age, drug duration, mean drug dose, and hospital duration did not differ between the two groups. Factors that affected survival included LDH $(p=0.042)$, BUN $(p=0.001)$, creatinine $(p=$ $0.003)$, sodium level $(p=0.001)$, potassium level $(p=$ $0.019)$, and ARF occurrence $(p=0.005)$. The severity of liver disease classified by Child-Pugh scoring was not different between the two groups (Table 4).

\section{Discussion}

Our study suggests that fenoverine treatment has correlation with rhabdomyolysis in patients with LC. The incidence of rhabdomyolysis was $2.03 \%$ in patients with $\mathrm{LC}$ and $0.04 \%$ in patients with normal liver function. This was accompanied by ARF in some cases (31.8\%), and mortality was significantly more common in this case. Deceased patients had both ARF and LC.

Hepatic derangement is one of the most important underlying diseases in fenoverine-associated rhabdomyolysis [17-20]. However, there has been no report on 
Table 3 Clinical and laboratory parameters in ARF group and non-ARF group

\begin{tabular}{|c|c|c|c|}
\hline $\begin{array}{l}\text { Clinical and } \\
\text { laboratory } \\
\text { parameters }\end{array}$ & $\begin{array}{l}\text { ARF group } \\
(n=7)\end{array}$ & $\begin{array}{l}\text { Non-ARF group } \\
(n=15)\end{array}$ & $P$ \\
\hline Age & $58.3 \pm 10.5$ & $58.1 \pm 9.6$ & 0.962 \\
\hline Sex & & & 0.671 \\
\hline Male (\%) & $5(71.4)$ & $9(60)$ & \\
\hline Female (\%) & $2(28.6)$ & $6(40)$ & \\
\hline Drug duration (days) & $15.9 \pm 7.8$ & $13.0 \pm 9.4$ & 0.494 \\
\hline Drug total dose (mg) & $4757.1 \pm 2345.8$ & $3753.3 \pm 2723.9$ & 0.412 \\
\hline WBC $\left(\times 10^{3} / \mathrm{uL}\right)$ & $9.4 \pm 5.4$ & $5.9 \pm 2.0$ & 0.034 \\
\hline CK (U/L) & $26,467.8 \pm 22,434.3$ & $18,601.6 \pm 11,893.8$ & 0.290 \\
\hline $\mathrm{LDH}(\mathrm{U} / \mathrm{L})$ & $2836.0 \pm 2497.6$ & $2080.1 \pm 712.3$ & 0.282 \\
\hline AST (U/L) & $1495.8 \pm 718.3$ & $967.3 \pm 553.9$ & 0.085 \\
\hline $\operatorname{ALT}(U / L)$ & $464.9 \pm 215.7$ & $350.8 \pm 240.8$ & 0.327 \\
\hline Albumin (g/dL) & $3.2 \pm 0.6$ & $2.7 \pm 0.6$ & 0.105 \\
\hline BUN (mg/dL) & $56.7 \pm 32.3$ & $17.3 \pm 6.9$ & $<0.001$ \\
\hline Creatinine $(\mathrm{mg} / \mathrm{dL})$ & $4.2 \pm 2.6$ & $0.8 \pm 0.3$ & $<0.001$ \\
\hline Sodium (mmol/L) & $131.1 \pm 6.5$ & $137.8 \pm 5.5$ & 0.020 \\
\hline Potassium (mmol/L) & $5.2 \pm 0.8$ & $4.3 \pm 0.4$ & 0.001 \\
\hline Hospital days & $17.6 \pm 9.8$ & $22.9 \pm 9.4$ & 0.234 \\
\hline \multicolumn{4}{|c|}{ Clinical signs and symptoms } \\
\hline Muscle pain (\%) & $7(100)$ & $13(86.7)$ & 0.545 \\
\hline $\begin{array}{l}\text { Muscle weakness } \\
(\%)\end{array}$ & $3(42.9)$ & $6(40.0)$ & 1.000 \\
\hline Oliguria (\%) & $4(57.1)$ & $0(0)$ & 0.005 \\
\hline Dark urine (\%) & $2(28.6)$ & $1(6.7)$ & 0.227 \\
\hline LC (\%) & $5(26.3)$ & $14(93.3)$ & 0.227 \\
\hline $\begin{array}{l}\text { Child-Pugh } \\
\text { classification }\end{array}$ & & & 0.312 \\
\hline A (\%) & $0(0)$ & $3(21.4)$ & \\
\hline B (\%) & $1(20.0)$ & $6(42.9)$ & \\
\hline C (\%) & $4(80.0)$ & $5(35.7)$ & \\
\hline $\begin{array}{l}\text { Severe hepatic } \\
\text { derangement }\end{array}$ & $4(80)$ & $5(35.7)$ & 0.376 \\
\hline Etiology of LC & & & 0.830 \\
\hline Hepatitis B (\%) & $3(60)$ & $9(64.3)$ & \\
\hline Hepatitis C (\%) & $1(20)$ & $1(5.3)$ & \\
\hline Alcohol (\%) & $1(20)$ & $3(25.1)$ & \\
\hline Cryptogenic (\%) & $0(0)$ & $1(5.3)$ & \\
\hline Death (\%) & $4(57.1)$ & $0(0)$ & 0.005 \\
\hline
\end{tabular}

WBC White Blood Cell, CK Creatine Kinase, LDH Lactate Dehydrogenase, AST Aspartate Transaminase, ALT Alaninine Transminase, BUN Blood Urea Nitrogen, DM Diabetes Mellitus, ARF Acute Renal Failure, LC Liver Cirrhosis

the incidence in patients with fenoverine use. Our study demonstrates that the incidence of fenoverine-associated rhabdomyolysis was $2.03 \%$ in patients with LC under normal posology of fenoverine, and that the incidence
Table 4 Clinical and laboratory characteristics in death group and survival group

\begin{tabular}{|c|c|c|c|}
\hline $\begin{array}{l}\text { Clinical and laboratory } \\
\text { parameters }\end{array}$ & $\begin{array}{l}\text { Death group } \\
(n=4)\end{array}$ & $\begin{array}{l}\text { Survival group } \\
(n=18)\end{array}$ & $P$ \\
\hline Age & $56.8 \pm 12.5$ & $58.4 \pm 9.3$ & 0.760 \\
\hline Sex & & & 0.671 \\
\hline Male (\%) & $5(71.4)$ & $9(60)$ & \\
\hline Female (\%) & $2(28.6)$ & $6(40)$ & \\
\hline Drug duration (days) & $15.0 \pm 6.5$ & $13.7 \pm 9.4$ & 0.792 \\
\hline Drug total dose (mg) & $4500 \pm 1944$ & $3977.8 \pm 2759.7$ & 0.726 \\
\hline WBC $\left(\times 10^{3} / \mathrm{uL}\right)$ & $9.0 \pm 7.1$ & $6.6 \pm 2.7$ & 0.254 \\
\hline CK (U/L) & $27,111.3 \pm 29,658.8$ & $19,769.7 \pm 12,078.8$ & 0.416 \\
\hline $\mathrm{LDH}(\mathrm{U} / \mathrm{L})$ & $3681.5 \pm 3142.2$ & $2018.2 \pm 710.6$ & 0.042 \\
\hline AST (U/L) & $1495.8 \pm 718.3$ & $967.3 \pm 553.9$ & 0.622 \\
\hline $\operatorname{ALT}(U / L)$ & $420.3 \pm 263.7$ & $374.6 \pm 235.1$ & 0.736 \\
\hline Albumin (g/dL) & $2.8 \pm 0.3$ & $2.8 \pm 0.7$ & 0.957 \\
\hline $\mathrm{BUN}(\mathrm{mg} / \mathrm{dL})$ & $64.7 \pm 22.5$ & $22.0 \pm 20.1$ & 0.001 \\
\hline Creatinine (mg/dL) & $4.5 \pm 1.9$ & $1.3 \pm 1.7$ & 0.003 \\
\hline Sodium (mmol/L) & $126.9 \pm 3.8$ & $137.6 \pm 5.2$ & 0.001 \\
\hline Potassium (mmol/L) & $5.3 \pm 0.9$ & $4.4 \pm 0.5$ & 0.019 \\
\hline Hospital days & $21.8 \pm 11.6$ & $21.1 \pm 9.6$ & 0.908 \\
\hline \multicolumn{4}{|c|}{ Clinical signs and symptoms } \\
\hline Muscle pain (\%) & $7(100)$ & $13(86.7)$ & 1.000 \\
\hline Muscle weakness (\%) & $3(42.9)$ & $6(40.0)$ & 0.616 \\
\hline Oliguria (\%) & $4(57.1)$ & $0(0)$ & 0.135 \\
\hline Dark urine (\%) & $2(28.6)$ & $1(6.7)$ & 1.000 \\
\hline LC (\%) & $4(100)$ & $15(83.3)$ & 1.000 \\
\hline Child-Pugh classification & & & 0.312 \\
\hline A (\%) & $0(0)$ & $3(20.0)$ & \\
\hline B (\%) & $0(0)$ & $7(46.7)$ & \\
\hline C (\%) & $4(100)$ & $5(33.3)$ & \\
\hline $\begin{array}{l}\text { Severe hepatic } \\
\text { derangement }\end{array}$ & $4(100)$ & $5(33.3)$ & 0.017 \\
\hline Etiology of LC & & & 1.000 \\
\hline Hepatitis B (\%) & $3(75)$ & $9(60)$ & \\
\hline Hepatitis C (\%) & $0(0)$ & $2(13.3)$ & \\
\hline Alcohol (\%) & $1(25)$ & $3(20)$ & \\
\hline Cryptogenic (\%) & $0(0)$ & $1(6,7)$ & \\
\hline ARF (\%) & $4(100)$ & $3(16.7)$ & 0.005 \\
\hline
\end{tabular}

WBC White Blood Cell, CK Creatine Kinase, LDH Lactate Dehydrogenase, AST Aspartate Transaminase, ALT Alaninine Transminase, BUN Blood Urea Nitrogen, $D M$ Diabetes Mellitus, ARF Acute Renal Failure, $L C$ Liver Cirrhosis

tended to increase with the degree of liver failure according to Child-Pugh classification, though there was no significant difference. This might result from the small sample size of LC patients. Our study also shows that the less frequent prescription of fenoverine in the 
high-risk group resulted in a lower occurrence of rhabdomyolysis.

Chichmanian et al. reported 45 cases of rhabdomyolysis induced by fenoverine [19]. The mean time to admission in that study was 11 days while it was 14 days in our study. They proposed that rhabdomyolysis may be induced by a modification in the hepatic first-pass effect of fenoverine; in 30 cases, there was chronic liver disease or an association with hepatic inhibitory drugs and with highly metabolized drugs. Our case study reveals that 18 patients had various degrees of underlying LC, while 4 patients had normal liver function. Four patients also had no underlying disease and used no medications known to induce hepatic inhibition or drug metabolism [19]. However, they did not describe any other clinical features or laboratory characteristics as we did.

Rhabdomyolysis is a potentially deadly syndrome that is often unrecognized. There are many etiologies of rhabdomyolysis. Drug-induced rhabdomyolysis is the leading cause of this syndrome. One study reported that drug-induced rhabdomyolysis, including alcohol, comprised up to $81 \%$ of rhabdomyolysis cases [24]. This category of rhabdomyolysis is complicated by the fact that there are primary and secondary mechanisms of muscle cell injury [11]. Primary toxic-induced rhabdomyolysis is induced by a direct attack on skeletal myocyte function and integrity. Secondary effects result from predisposing risk factors such as local muscle compression in coma, prolonged seizures, trauma, and metabolic abnormalities $[11,24]$. Chariot et al. also described two patients with fenoverine-associated rhabdomyolysis [18]. They suggested that focal muscle necrosis and regeneration on muscle biopsy might be associated with the muscular toxicity of fenoverine, and that ischemia may be one mechanism of fenoverine-induced rhabdomyolysis.

Jouglad et al. studied the predisposition for acute rhabdomyolysis attributed to fenoverine in 7 patients without underlying hepatic dysfunction [25]. They investigated all patients with the following tests: 31-phosphorus nuclear magnetic resonance spectroscopy, histopathological muscle findings, muscle contraction tests, and biochemical analyses of the muscle. All patients had muscle abnormalities and oxidative dysfunction induced by fenoverine. They concluded that there is a cause-and-effect link between underlying abnormalities and muscular cytolysis attributed to fenoverine. However, no patient had previously presented with clinical signs of a muscular disorder before fenoverine intake. This means that it is impossible to predict a patient's predisposition to fenoverine toxicity before taking the medication if the patient has no underlying hepatic dysfunction.

The mortality rate in patients with rhabdomyolysis varies from 10 to $25 \%$. The major cause of death is underlying disease progression [26, 27]. Kim et al. showed that the development of ARF and the presence of oliguria may be the most important prognostic factors [26]. Our results show that the mortality rate in fenoverine-induced rhabdomyolysis was $18.2 \%$, and it was higher in the ARF group than in the non-ARF group. All deceased patients had poor hepatic function (Child-Pugh classification C) accompanied by oliguric ARF; no deaths occurred among patients with normal hepatic function. However, this does not mean that fenoverine was the direct cause of hepatic disease progression. Rather, disease progression and fenoverine administration likely occurred together by chance. Previous reports showed that fenoverine-associated rhabdomyolysis in patients with hepatic derangement led to death [18], while other studies of fenoverine-associated rhabdomyolysis did not shown any mortalities, even in patients with poor hepatic function $[17,19,20,22]$.

The most worrying limitation of our study is that the incidence of fenoverine-associated rhabdomyolysis might be underestimated because only hospitalized patients were included and subclinical presentations without common features such as myalgia, myoglobinuria, and those whose CK has risen slightly above the diagnostic criteria CK may have been overlooked. Another limitation is that we might not have been able to completely exclude other causes of rhabdomyolysis due to the characteristics of the retrospective analysis (depending on medical records). Other limitations also exist that enrolled patients were only limited to cases of rhabdomyolysis in patients who have been prescribed with fenoverine and diagnosed in our hospital. It was excluded from cases where patients were prescribed at our hospital and diagnosed with rhabdomyolysis at another hospital. Since we have searched and enrolled patients with prescription and disease codes, there is a possibility that data will be less accurate leading to underestimate the incidence of rhabdomyolysis. Another limitation of our study, which has relatively long retrospective study, includes that rhabdomyolysis patients in the second period could receive better cares resulting in the improvement of prognosis. Furthermore, the incidence in LC patients may be more accurate and higher than in patients with normal hepatic function because of frequent and periodic follow up at the hospital. Above all, The number of sampling size is so small that it is considered difficult to generalize the results of this research. However, it is meaningful that we included many patients taking fenoverine at a single center, especially LC patients.

\section{Conclusions}

Fenoverine might be associated with rhabdomyolysis in patients with severe hepatic dysfunction and fatal in 
these patients with the occurrence of ARF. Therefore, physicians should carefully prescribe fenoverine in patients with LC.

\section{Abbreviations}

ARF: Acute renal failure; ALT: Alanine aminotransaminase; AST: Aspartate transaminase; BUN: Blood urea nitrogen; CK: Creatinine kinase; LC: Liver cirrhosis; LDH: Lactate dehydrogenase

\section{Acknowledgements}

The authors would like to thank all the colleagues who participate in this project.

\section{Financial disclosure and conflicts of interest}

None declared.

\section{Ethics committee approval}

The study protocol was approved by the Institutional Review Board of Gyeongsang National University Hospital (IRB no. 2013-03-018).

\section{Authors' contributions}

SC and DJP designed the study. JC and JN initially drafted the manuscript and performed the statistical analyses. EB, TEL, HJ, and HSC collected and interpreted the data. EB and DJP prepared, reviewed, and revised the manuscript. DJP further supervised the work. All authors contributed to and approved the final manuscript

\section{Funding}

No funding was received for this study.

\section{Availability of data and materials}

The datasets used and/or analyzed during this study are available from the corresponding author on reasonable request.

\section{Ethics approval and consent to participate}

We respected all patients' rights to privacy and protected their identity. The study protocol was approved by the Institutional Review Board of Gyeongsang National University Hospital (IRB no. 2013-03-018), who waived the need for informed consent. All individual information was deidentified.

\section{Consent for publication}

Not applicable.

\section{Competing interests}

The authors declare that they have no competing interests.

\section{Author details}

'Department of Internal Medicine, Changwon Gyeongsang National University Hospital, Changwon, South Korea. ${ }^{2}$ Department of Internal Medicine, College of Medicine, Gyeongsang National University, Jinju, South Korea. ${ }^{3}$ Department of Internal Medicine, Gyeongsang National University Hospital, Jinju, South Korea. ${ }^{4}$ Institute of Health Science, Gyeongsang National University, Jinju, South Korea.

\section{Received: 3 January 2020 Accepted: 14 April 2020}

\section{Published online: 25 April 2020}

\section{References}

1. Sauret JM, Marinides G, Wang GK. Rhabdomyolysis. Am Fam Physician. 2002; 65:907-12

2. Warren JD, Blumbergs PC, Thompson PD. Rhabdomyolysis: a review. Muscle Nerve. 2002:25:332-47.

3. Visweswaran P, Guntupalli J. Rhabdomyolysis. Crit Care Clin. 1999;15:415-28.

4. Vanholder R, Sever MS, Erek E, Lameire N. Rhabdomyolysis. J Am Soc Nephrol. 2000;11:1553-61.

5. Bosch X, Poch E, Grau JM. Rhabdomyolysis and acute kidney injury. N Engl J Med. 2009;361:62-72.

6. Holt SG, Moore KP. Pathogenesis and treatment of renal dysfunction in rhabdomyolysis. Intensive Care Med. 2001;27:803-11.
7. Lameire N, Matthys E, Vanholder R, De Keyser K, Pauwels W, Nachtergaele H, Lambrecht L, Ringoir $\mathrm{S}$. Causes and prognosis of acute renal failure in elderly patients. Nephrol Dial Transplant. 1987;2:316-22.

8. Bagley WH, Yang H, Shah KH. Rhabdomyolysis. Intern Emerg Med. 2007;2: 210-8.

9. Khan FY. Rhabdomyolysis: a review of the literature. Neth J Med. 2009;67: 272-83.

10. Lane R, Philps M. Rhabdomyolysis has many causes, including statins, and may be fatal. BMJ. 2003:327:115-6.

11. Coco TJ, Klasner AE. Drug-induced rhabdomyolysis. Curr Opin Pediatr. 2004; 16:206-10.

12. Hohenegger M. Drug-induced rhabdomyolysis. Curr Opin Pharmacol. 2012; 12:335-9.

13. Camarri E. Fenoverine: smooth muscle synchronizer for the management of gastro-intestinal conditions. II. A trimebutine-controlled, double-blind, crossover clinical evaluation. Curr Med Res Opin. 1986;10:52-7.

14. Gonella J, Lalanne C, Mironneau J. Fenoverine: a novel synchronizer of smooth muscle motility by interference with cellular calcium flow. Curr Med Res Opin. 1987;10:427-35.

15. Hébuterne X, Chichmanian RM, Cohen HL, Rampal P. Acute rhabdomyolysis due to fenoverine. Gastroenterol Clin Biol. 1991;15:861-2.

16. Hardin JM, Guillebaud JC, Lallement PY, Matta B, Andrejak M. Rhabdomyolysis associated to fenoverine therapy and complicated by acute renal failure. Therapie. 1992:47:165-6.

17. Ouakil H, Pouchot J, Debin ML, Le Bourdelles G, Coste F, Vinceneux P. Acute rhabdomyolysis caused by fenoverine. Rev Med Interne. 1994;15:695-6.

18. Chariot P, Ratiney R, Le Maguet F, Fourestié V, Astier A, Gherardi R. Fenoverine-induced rhabdomyolysis. Hum Exp Toxicol. 1995;14:654-6.

19. Chichmanian RM, Spreux A, Bouillet M, Chiffoleau A, Baudot S, Larousse C. Rhabdomyolyses dues a la fenoverine: analyse de 45 cas. Rev Med Interne. 1992;13:S114.

20. Park SY, Lee $\mathrm{K}$, Song $\mathrm{JH}$, et al. Fenoverine-induced rhabdomyolysis in a patient with liver cirrhosis, Korean J Nephrol. 2001:20:501-5.

21. Kim KH, Sim MR, Kye YH, et al. A case of fenoverine-induced rhabdomyolysis in diabetic nephropathy. Korean J Med. 2002:62:465-8.

22. Na KR, Jeong S, Jang DS, et al. 3 cases of Fenoverine-induced rhabdomyolysis. Korean J Nephrol. 2005;24:680-5.

23. Chavez LO, Leon M, Einav S, Varon J. Beyond muscle. Destruction: a systematic review of rhabdomyolysis for clinical practice. Crit Care. 2016; 20(1):135.

24. Prendergast BD, George CF. Drug- induced rhabdomyolysis: mechanisms, and management. Postgrad Med J. 1993;69:333-6.

25. Jouglard J, Kozak-Ribbens G, de Haro L, Cozzone PJ. Research into individual predisposition to develop acute rhabdomyolysis attributed to fenoverine. Hum Exp Toxicol. 1996;15:815-20

26. Kim HY, Choi OS, Shin SJ, et al. Analysis of 250 cases of rhabdomyolysis. Korean I Nephrol. 1994;13:810-7.

27. Gabow PA, Kaehny WD, Kelleher SP. The spectrum of rhabdomyolysis. Medicine (Baltimore). 1982;61:141-52

\section{Publisher's Note}

Springer Nature remains neutral with regard to jurisdictional claims in published maps and institutional affiliations.

Ready to submit your research? Choose BMC and benefit from:

- fast, convenient online submission

- thorough peer review by experienced researchers in your field

- rapid publication on acceptance

- support for research data, including large and complex data types

- gold Open Access which fosters wider collaboration and increased citations

- maximum visibility for your research: over $100 \mathrm{M}$ website views per year

At BMC, research is always in progress.

Learn more biomedcentral.com/submission 